\title{
ỨNG DỤNG MÔ HÌNH THỦY VĂN-THỦY LỰC KẾT HợP MƯA DỬ BÁO IFS PHỤC VỤ CẢNH BÁO LŨ, NGẬP LỤT HẠ LU'U SỐNG VU GIA-THU BỒN
}

\author{
Đoàn Quang Trí
}

Tóm tắt: Nghiên cứu ưng dụng mô hình hóa trong vấn đề cảnh báo, dụ báo lũ, ngập lụt đã được quan tâm nghiên cưu gần đây. Nghiên cứu này áp dụng kết hợp bộ mô hình thủy văn MIKE SHE, mô hình thủy lục MIKE 11 và mô hình MIKE 11 GIS để mô phỏng, cảnh báo ngập lụt cho khu vục hạ lưu sông Vu Gia-Thu Bồn, Việt Nam. Nghiên cưu sủ dụng mưa tù mô hình số trị IFS làm đầu vào cho mô hình thủy văn thủy lực. Kết quả hiệu chỉnh và kiểm định mô hình thủy văn MIKE SHE và mô hình thủy lực MIKE 11 chỉ ra rằng mô hình có khả năng mô phỏng tốt. Kết quả so sánh quá trình lưu lương, mưc nước tính toán và thực đo có sự tương đồng cao về pha và biên độ dao động dụa theo 03 chi số đánh giá NSE, RSR và PBIAS. Kết quả mô phỏng cảnh báo ngập cho khu vưc hạ lưu theo cấp báo động và mức lũ lịch sủ sẽ đưa ra nhũng kết quả thống kê về diện tích ngập, mức độ ngập hỗ trợ cho công tác ứng phó khắc phục sụ cố khi có thiên tai xảy ra.

Từ khóa: IFS, MIKE SHE, MIKE 11-MIKE 11 GIS, Ngập lut, Vu Gia-Thu Bồn.

Ban Biên tập nhận bài: 12/04/2019 Ngày phản biện xong: 28/6/2019 Ngày đăng bài: 25/07/2019

\section{1. Đặt vấn đề}

Trong những năm gần đây vấn đề cảnh báo, dự báo lũ, đặc biệt lũ lớn, lũ lịch sử ở khu vực miền Trung đã được quan tâm nghiên cứu khá nhiều. Từ khi các hệ thống hồ chứa ở Việt Nam đi vào hoạt động, dự báo lũ đã trở thành một nhiệm vụ quan trọng phục vụ việc điều hành hồ chống lũ cho hạ du và sản xuất điện năng. Đây là một vấn đề hết sức phức tạp được nhiều nhà nghiên cứu trong và ngoài nước quan tâm. Trong một vài năm trở lại đây việc ứng dụng mô hình số trị trong nghiên cứu khí tượng nói chung và dự báo thời tiết nói riêng đã được phát triển mạnh mẽ ở nước ta [1]. Trung tâm Dự báo Khí tượng Thủy văn quốc gia (TTDBQG) đã đầu tư nghiên cứu và đưa vào sử dụng một số công nghệ hiện đại trong dự báo mưa số trị [2-3]. Từ năm 2012 đến nay, TTDBQG đã được Bộ Tài nguyên và Môi trường đầu tư dự án mua các sản phẩm (dạng ảnh có sẵn trên trang web) và số liệu dạng số của Trung tâm Dự báo hạn vừa Châu Âu ${ }^{\prime}$ Tạp chí Khi tượng Thủy văn, Tổng cục Khí tuợng Thủy văn

Email:doanquangtrikttv@gmail.com
(ECMWF) để phục vụ công tác dự báo nghiệp vụ. Đây là nguồn số liệu dự báo khí tượng toàn cầu toàn diện nhất mà TTDBQG có thể khai thác và sử dụng trong công tác nghiệp vụ. Nghiên cứu này đã sử dụng sản phẩm mưa dự báo IFS làm đầu vào cho việc mô phỏng, dự báo dòng chảy tới hồ và cảnh báo ngập lụt cho khu vực hạ lưu trên lưu vực sông Vu Gia-Thu Bồn. Hiện nay rất nhiều mô hình toán thủy văn, thủy lực 1-2 chiều đã được nghiên cứu để ứng dụng trên các hệ thống sông miền Trung [4-6], nhưng chỉ rất ít trong số đó có thể ứng dụng được trong nghiệp vụ dự báo hàng ngày: mô hình Wetspa kết hợp với mô hình thủy lực HEC-RAS đã nghiên cứu và ứng dụng thành công trên lưu vực sông $\mathrm{Vu}$ Gia - Thu Bồn [7]; bộ mô hình MIKE (MIKE NAM, MIKE 11-GIS, MIKE FLOOD) cho sông Thạch Hãn [8]; mô hình thủy lực TELEMAC$2 \mathrm{D}$ kết hợp với MIKE NAM cho vùng hạ lưu hệ thống sông Trà Khúc - Sông Vệ [9-10]. Mô hình thủy văn thông số phân bố MIKE SHE được sử dụng nhiều nơi trên thế giới, tuy nhiên ở Việt Nam những nghiên cứu ứng dụng MIKE SHE còn chưa nhiều [11-12]. Mô hình MIKE SHE có 


\section{BÀI BÁO KHOA HỌC}

khả năng mô phỏng quá trình mưa-dòng chảy trên từng ô lưới theo không gian, phù hợp với việc sử dụng số liệu mưa số trị từ mô hình IFS [12]. Việc kết hợp sử dụng số liệu mưa từ mô hình số trị IFS làm đầu vào cho mô hình thủy văn, thủy lực phục vụ cảnh báo, dự báo lũ, ngập lụt cho khu vực hạ lưu là một hướng mới trong việc áp dụng mô hình hóa trong công tác nghiệp vụ tại TTDBTU. Mục đích của nghiên cứu này: (1) Ứng dụng sản phẩm của mô hình IFS làm đầu vào cho mô hình thủy văn; (2) Nghiên cứu ứng dụng mô hình thủy văn thông số phân bố
MIKE SHE tính toán lưu lượng làm đầu vào cho mô hình thủy lực MIKE 11; (3) Úng dụng công cụ Viễn thám GIS trong MIKE 11 GIS để mô phỏng, diễn toán thủy lực, cảnh báo ngập lụt cho khu vực hạ lưu.

\section{Phương pháp nghiên cứu và thu thập tài} liệu

Hình 1 miêu tả đầy đủ quá trình nghiên cứu từ thu thập dữ liệu đầu vào, ứng dụng dữ liệu mưa số trị IFS, áp dụng mô hình MIKE SHE, MIKE 11 và MIKE 11 GIS trong việc xây dựng bản đồ ngập lụt hạ lưu sông Vu Gia-Thu Bồn.

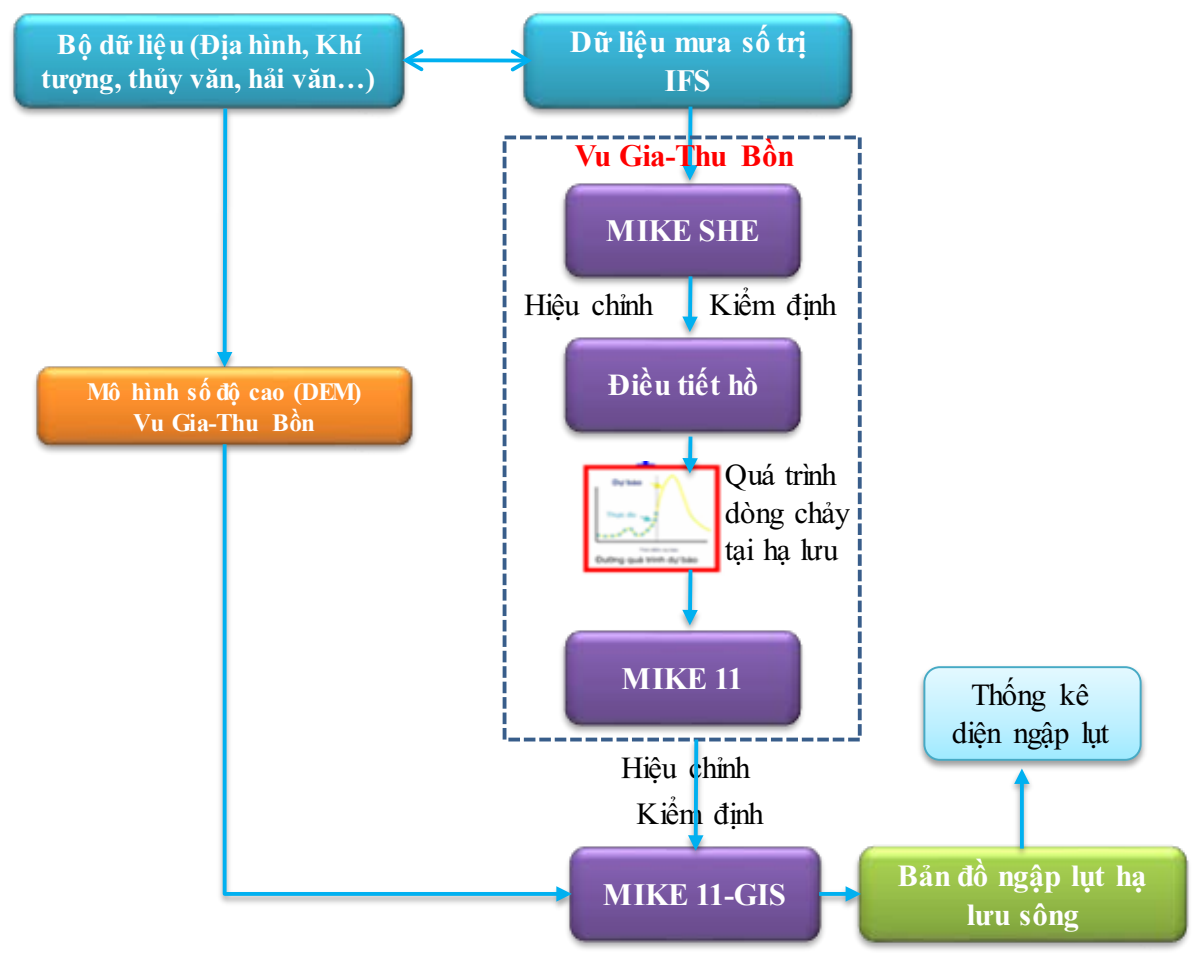

Hình 1. So đồ tổng thể quá trình nghiên cưu

\subsection{Giới thiệu vị trí khu vục nghiên cúu}

Hệ thống sông Vu Gia-Thu Bồn là một trong 9 hệ thống sông lớn ở nước ta và là hệ thống sông lớn nhất ở khu vực Trung Trung Bộ. Lưu vực sông Vu Gia-Thu Bồn được giới hạn ở phía bắc bởi dãy núi Bạch Mã là một nhánh núi đâm ra biển ở phần cuối dãy Trường Sơn Bắc, phía tây là khối núi Nam - Ngãi - Định thuộc phần đầu của dãy Trường Sơn Nam với những đỉnh núi cao trên $2000 \mathrm{~m}$, phía tây nam là khối núi Kon Tum với đỉnh Ngọc Linh cao 2598m, phía nam là dãy núi Nam Ngãi và phía đông là biển. Hệ thống sông Vu Gia-Thu Bồn với diện tích
$11.390 \mathrm{~km}^{2}$ bao trùm hầu hết lãnh thổ thành phố Đà Nẵng và tỉnh Quảng Nam, trong đó có khoảng $500 \mathrm{~km}^{2}$ ở thượng nguồn sông Cái nằm ở tỉnh Kon Tum (Hình 2). Tổng lượng mưa, cường độ mưa, phân bố mưa quyết định quá trình hình thành dòng chảy lũ trên sông. Mưa gây lũ ở vùng ven biển Miền Trung nói chung và hệ thống sông $\mathrm{Vu}$ Gia-Thu Bồn nói riêng thường do các hình thái thời tiết như: bão, áp thấp nhiệt đới, không khí lạnh, dải hội tụ nhiệt đới và các nhiễu động nhiệt đới khác như gió đông (chủ yếu là sóng đông) gây nên. Các hình thế thời tiết này đơn độc hoặc kết hợp với nhau cùng tác động. 
Đặc điểm lũ trong hệ thống sông Vu Gia-Thu Bồn là lũ lên nhanh, xuống nhanh với biên độ và cường suất lũ lớn ở thượng và trung lưu, lũ lên tương đối nhanh nhưng rút chậm ở hạ lưu. Hình
3 trình bày sơ đồ hóa các trạm khí tượng thủy văn và hệ thống hồ chứa thủy điện trên lưu vực Vu Gia-Thu Bồn.

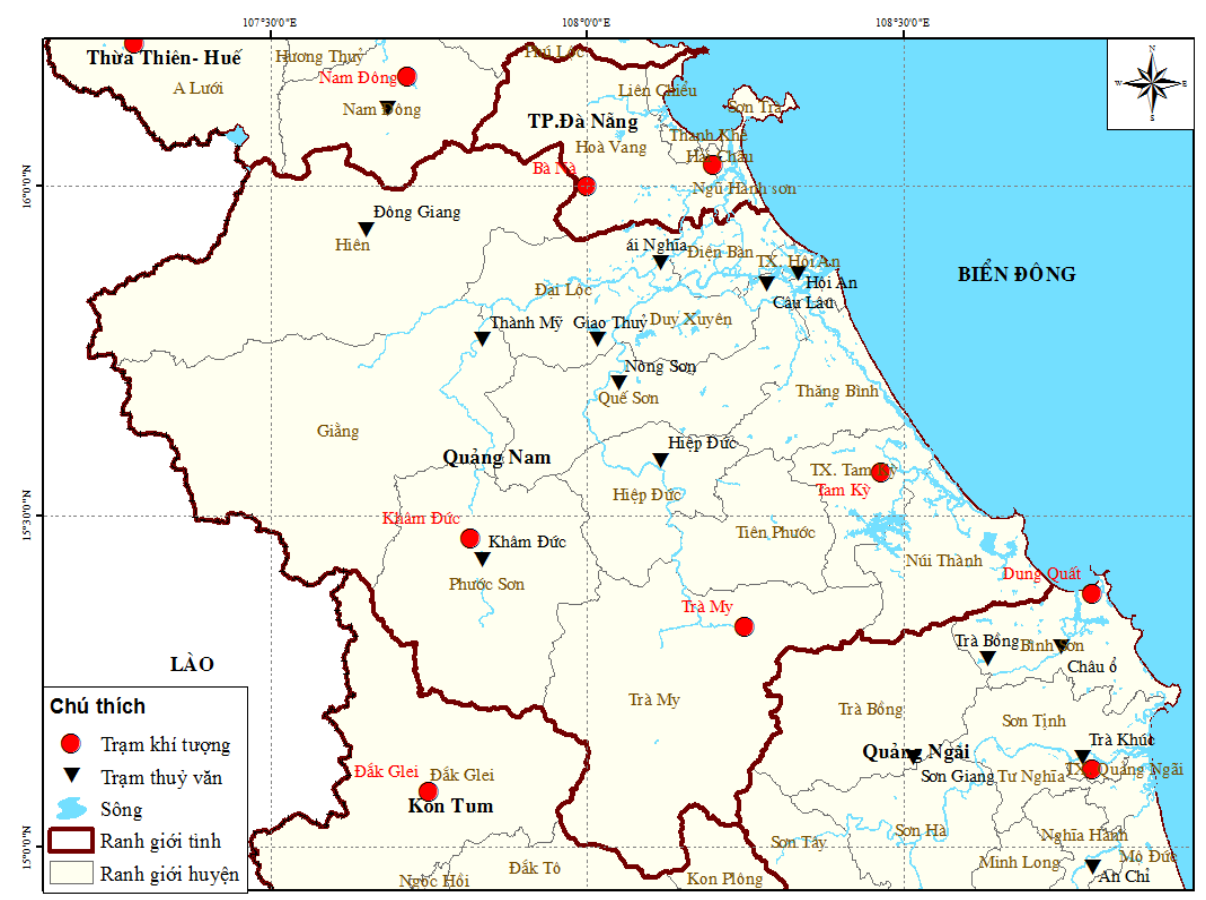

Hình 2. Bản đồ mạng lưới trạm khí tượng thuỷ văn lưu vực sông Vu Gia-Thu Bồn

\subsection{Thu thập tài liệu}

+ Số liệu khí tượng: Nghiên cứu sử dụng số liệu mưa, số liệu bốc hơi tại các trạm khí tượng và điểm đo mưa trong lưu vực: Trà My, Tam Kỳ, Nông Sơn, Hội An, Ái Nghĩa, Khâm Đức, Câu Lâu, Giao Thuỷ, Đà Nẵng, Thành Mỹ. Số liệu mưa sử dụng sản phẩm từ mô hình số trị IFS.

+ Số liệu thủy văn và hải văn: Số liệu lưu lượng và mực nước tại các trạm thuỷ văn: Ái Nghĩa, Thành Mỹ, Câu Lâu, Giao Thuỷ, Hội Khách, Nông Sơn.

+ Số liệu địa hình: Mặt cắt ngang hệ thống sông Vu Gia-Thu Bồn, Bản đồ địa hình lưu vực Vu Gia-hu Bồn, Bản đồ sử dụng đất lưu vực $\mathrm{Vu}$ Gia-Thu Bồn, Bản đồ thảm phủ thực vật lưu vực Vu Gia-Thu Bồn.

\subsection{Giới thiệu mô hình MIKE SHE}

MIKE SHE là một mô hình thủy văn thông số phân bố dựa trên các quá trình vật lý được tích hợp đầy đủ, mô hình này có khả năng mô phỏng các quá trình thủy văn tại một điểm, trên một diện rộng, quy mô lưu vực, quá trình vận chuyển các phần tử, và có thể được liên kết với MIKE 11 để mô phỏng các mối quan hệ trong lưu vực sông. Mô hình MIKE SHE ban đầu được phát triển bởi ba tổ chức châu Âu (Viện Thủy lực Đan Mạch, Viện Thủy văn Anh và một công ty tư vấn Pháp SOGREAH) vào năm 1977. DHI đã dẫn đầu trong việc phát triển và nghiên cứu MIKE SHE để cải thiện và bổ sung [13-14]. Bản chất vật lý của mô hình bao gồm quá trình mô phỏng địa hình tự nhiên và các đặc điểm của lưu vực như thực vật, đất và thời tiết.

Bản chất phân tán của mô hình cho phép người dùng thay đổi các bộ tham số theo không gian và thời gian như: sử dụng đất, hệ thống thoát nước, dữ liệu thời tiết và bốc hơi, các giá trị dòng chảy trên mặt đất. Sự phân bố không gian được thực hiện thông qua một mạng lưới trực giao cho phép phân loại theo chiều ngang hoặc dọc, được áp dụng trong mỗi bộ tham số [15-16]. Phân phối thời gian cho phép người dùng thay đổi các tham số theo thời gian hoặc đặt các giá trị không đổi cho các tham số cho toàn bộ thời gian mô phỏng. Người dùng cũng có thể thay đổi độ phức tạp quá trình mô phỏng bằng cách điều 


\section{BÀI BÁO KHOA HỌC}

chỉnh thiết lập mô-đun của mô hình trong giao nước (ET), và dòng chảy bão hoà (SF) (Hình 3). diện người dùng. MIKE SHE bao gồm các mô- Nếu mô-đun dòng chảy bão hòa được chọn thì đun: Dòng chảy tràn $(\mathrm{OF})$, sông và hồ $(\mathrm{OC})$, trong đó sẽ bao gồm mô đun UZ và $\mathrm{ET}$. dòng chảy chưa bão hoà (UZ), bốc thoát hơi

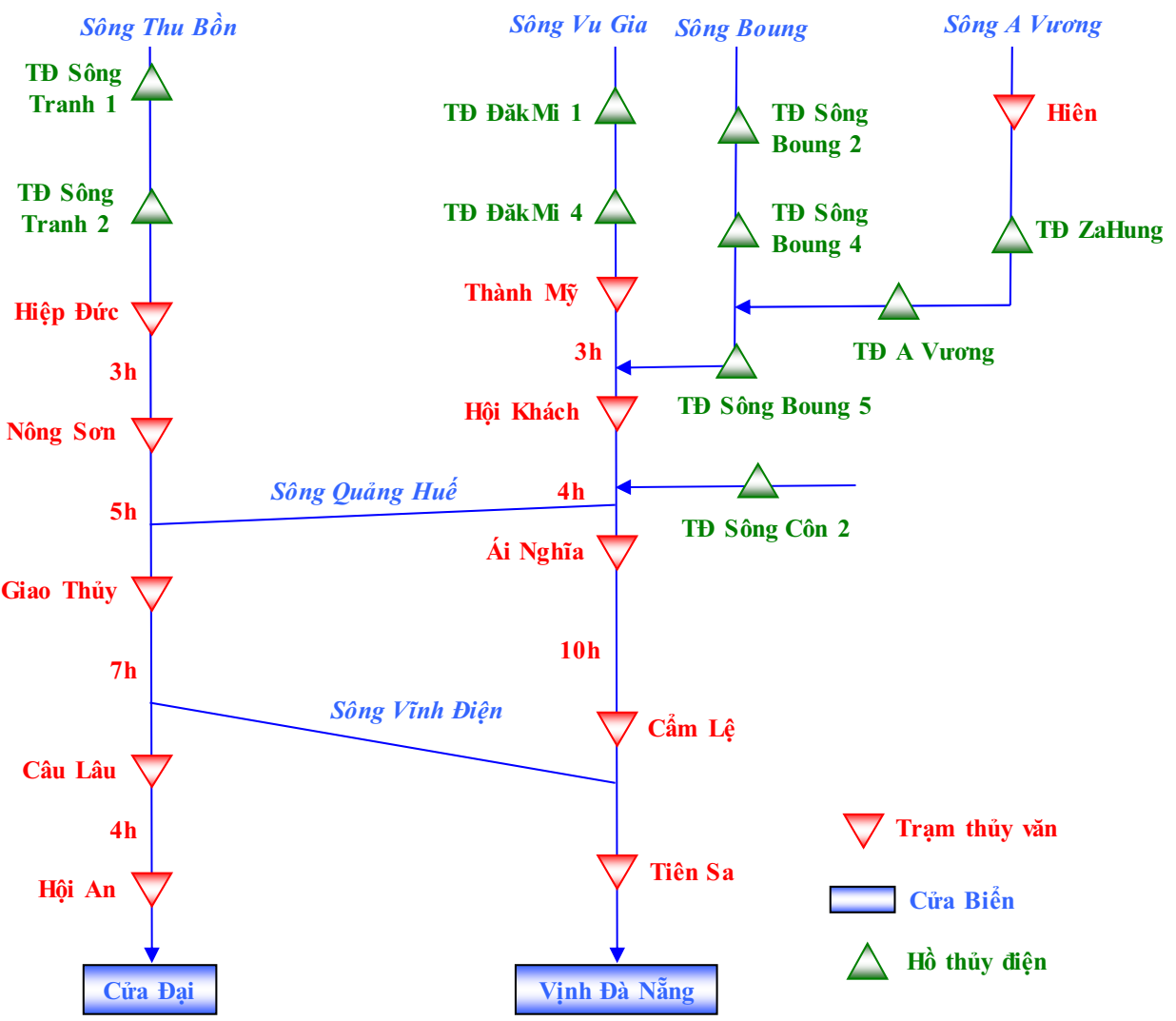

Hình 3. So đồ khối các trạm khí tương thủy văn và hồ thủy điện trên lưu vục Vu Gia-Thu Bồn

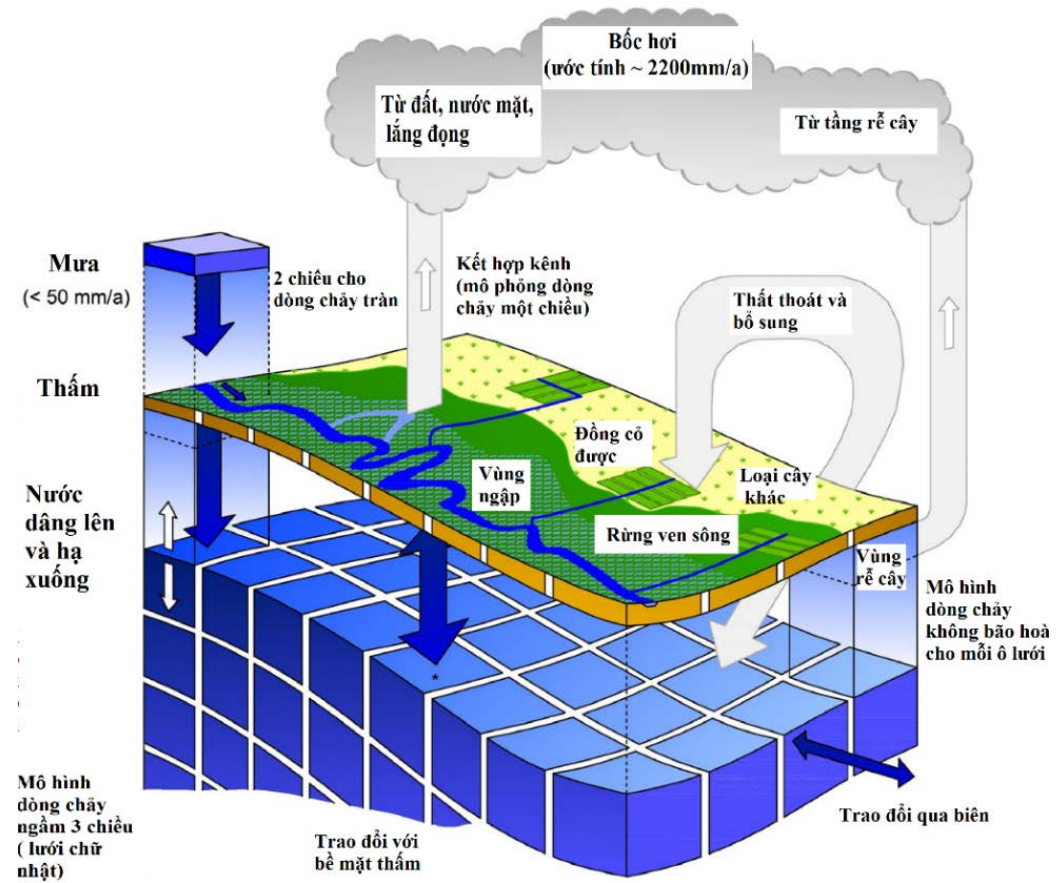

Hình 4. So đồ mô phỏng trong mô hình MIKE SHE [13-14] 


\subsection{Giới thiệu mô hình MIKE 11 và MIKE 11 GIS}

Mô hình MIKE 11 là bộ mô hình một chiều được phát triển bởi Viện thủy lực Đan Mạch (DHI) từ mô hình gốc đầu tiên ra đời năm 1972 dùng để mô phỏng thủy lực nước trong sông [17]. Mô đun thủy lực trong MIKE 11 HD có khả năng mô phỏng dòng chảy không ổn định trong hệ thống sông và cửa sông, có thể áp dụng cho mạng sông phân nhánh và mạng sông phức tạp. Kết quả mô phỏng của mô đun HD là diễn biến mực nước, lưu lượng. Mô đun thuỷ động lực học xây dựng trên cơ sở lý thuyết của hệ phương phương trình Saint-Venant, có dạng:

$$
\begin{gathered}
\frac{\partial \mathrm{Q}}{\partial \mathrm{x}}+\mathrm{b} \frac{\partial \mathrm{h}}{\partial \mathrm{t}}=\mathrm{q} \\
\frac{\partial \mathrm{Q}}{\partial \mathrm{t}}+\frac{\partial\left(\alpha \frac{\mathrm{Q}^{2}}{\mathrm{~A}}\right)}{\partial \mathrm{x}}+\mathrm{gA} \frac{\partial \mathrm{h}}{\partial \mathrm{x}}+\frac{\mathrm{gQ}|\mathrm{Q}|}{\mathrm{C}^{2} \mathrm{AR}}=0
\end{gathered}
$$

Trong đó $\mathrm{Q}$, h là lưu lượng và mực nước dòng chảy; $\mathrm{A}, \mathrm{b}$ là diện tích và chiều rộng mặt cắt; $\mathrm{g}$ là gia tốc trọng trường; $\mathrm{x}, \mathrm{t}$ là biến số khoảng cách và thời gian; $\alpha$ là hệ số hiệu chỉnh lưu tốc; $\mathrm{C}$ là hệ số Chezy; $\mathrm{R}$ là bán kính thuỷ lực.

MIKE 11 GIS có thể mô phỏng diện ngập lớn nhất, nhỏ nhất hay diễn biến từ lúc nước lên cho tới lúc nước xuống trong một trận lũ. Độ chính xác của kết quả tính từ mô hình và thời gian tính toán phụ thuộc rất nhiều vào độ chính xác của DEM. Nó cho biết diện ngập và độ sâu tương ứng từng vùng nhưng không xác định được hướng dòng chảy trên đó. MIKE 11 GIS là công cụ hỗ trợ lý tưởng trong công tác quản lý lũ bằng cách cung cấp một cách trực quan các động tác của lũ lên cộng đồng dân cư, hệ thống cơ sở hạ tầng, nông nghiệp, thủy sản và môi trường. Để xây dựng ứng dụng MIKE 11 GIS cần phải có những thông tin thiết yếu như mạng lưới sông MIKE 11, mô phỏng MIKE 11 và mô hình cao độ số DEM. Mô hình mạng lưới sông được đưa vào quy chiếu địa lý trong MIKE 11 GIS thông qua hệ thống diễn toán nhánh (Branch Route System - BRS). Bằng cách kết nối file mô phỏng của mô hình BRS, MIKE 11 GIS tạo ra các loại bản đồ lũ: bản đồ độ sâu/diện tích ngập, bản đồ thời gian.

\section{5 Đánh giá mô hình}

Việc ứng dụng các công cụ mô hình hóa trong quản lý tài nguyên nước đang ngày một phổ biến và hiệu quả nhằm mục đích dự đoán những thay đổi trong tương lai về khí hậu, thay đổi về tình hình sử dụng đất và cây trồng cũng như phục vụ quản lý số lượng và chất lượng tài nguyên nước và đất tốt hơn [18-20]. Tuy nhiên, để đánh giá khả năng của các mô hình này để đưa ra dự đoán một cách chính xác vẫn cần được kiểm nghiệm bằng các chỉ số đánh giá mô hình cho phù hợp [21-23]. Trong bài báo này đã sử dụng 03 chỉ số để đánh giá chất lượng của mô hình so với số liệu quan trắc thực tế bao gồm: NSE, RSR và PBIAS. Tiêu chí đánh giá chất lượng cho các chỉ số được trình bày trong bảng 1 .

Nash và Sutcliffe (NSE) (1970) [24] là phương pháp phổ biến và đáng tin cậy nhất để đánh giá chất lượng của các mô hình thủy văn. Chỉ số NSE được tính toán theo công thức 3 . Các giá trị NSE nằm trong khoảng từ 0 đến 1 . Một sự phù hợp tốt nhất được biểu thị bằng giá trị 1 trong khi 0 biểu thị sự phù hợp kém. Andersen và cs (2001) [25] đã chỉ ra rằng $\mathrm{NSE}$ trong khoảng từ 0,5 đến 0,95 thể hiện kết quả mô phỏng tốt. Hiện nay trong các nghiên cứu đánh giá mô hình thủy văn việc sử dụng chỉ tiêu NSE như là một công cụ phổ biến trong hầu hết các nghiên cứu [23].

$$
\mathrm{NSE}=1-\frac{\sum_{\mathrm{i}=1}^{\mathrm{N}}\left(\mathrm{Q}_{\mathrm{iTD}}-\mathrm{Q}_{\mathrm{iTT}}\right)^{2}}{\sum_{\mathrm{i}=1}^{\mathrm{N}}\left(\mathrm{Q}_{\mathrm{iTD}}-\overline{\mathrm{Q}}_{\mathrm{iTD}}\right)^{2}}
$$

Tỉ số độ lệch quan trắc tiêu chuẩn RMSE-observations standard deviation ratio (RSR) là một sai số thống kê giúp bình thường hóa RMSE với độ lệch chuẩn của dòng chảy thực đo. Tỉ số độ lệch quan trắc tiêu chuẩn được tính theo công thức 4.

$$
\mathrm{RSR}=\frac{\operatorname{RMSE}}{\operatorname{STDEV}_{\mathrm{obs}}}=\frac{\sqrt{\sum_{\mathrm{i}=1}^{\mathrm{n}}\left(\mathrm{Q}_{\mathrm{i}}^{\mathrm{td}}-\mathrm{Q}_{\mathrm{i}}^{\mathrm{tt}}\right)^{2}}}{\sqrt{\sum_{\mathrm{i}=1}^{\mathrm{n}}\left(\mathrm{Q}_{\mathrm{i}}^{\mathrm{td}}-\mathrm{Q}^{\mathrm{TB}}\right)^{2}}}
$$


Gupta và cs (1999) [26] đã chỉ ra rằng phần trăm BIAS (PBIAS) là một loại phân tích sai số thống kê định lượng khả năng mô phỏng các giá trị của mô hình để đánh giá giới hạn dao động của chuỗi dữ liệu quan trắc được. PBIAS có thể được tính toán bằng cách sử dụng công thức 5 .

$$
\text { PBIAS }=\frac{\sum_{\mathrm{i}=1}^{\mathrm{N}}\left(\mathrm{Q}_{\mathrm{iTD}}-\mathrm{Q}_{\mathrm{iTT}}\right) \times 100}{\sum_{\mathrm{i}=1}^{\mathrm{N}} \mathrm{Q}_{\mathrm{iTD}}}
$$

Trong đó $\mathrm{Q}_{\mathrm{iTT}}$ là giá trị lưu lượng thực đo; $\overline{\mathrm{Q}}_{\mathrm{iTD}}$ là giá trị lưu lượng tính toán; là giá trị lưu lượng trung bình thực đo; $\mathrm{N}$ là số lượng giá trị thực đo.

Bảng 1. Tiêu chí đánh giá chất lượng cho các chỉ số [18]

\begin{tabular}{lccc}
\hline \multicolumn{1}{c}{ Đánh giá } & RSR & NSE & PBIAS $(\%)$ \\
\hline Rất tốt & $0 \leq \mathrm{RSR} \leq 0,5$ & $0,75<\mathrm{NSE} \leq 1$ & PBIAS $< \pm 10$ \\
Tốt & $0,5 \leq \mathrm{RSR} \leq 0,6$ & $0,65<\mathrm{NSE} \leq 0,75$ & $\pm 10 \leq \mathrm{PBIAS}< \pm 15$ \\
Đạt yêu cầu & $0,6 \leq \mathrm{RSR} \leq 0,7$ & $0,5<\mathrm{NSE} \leq 0,65$ & $\pm 15 \leq \mathrm{PBIAS}< \pm 25$ \\
Không đạt & $\mathrm{RSR}>0,7$ & $\mathrm{NSE} \leq 0,5$ & PBIAS $\geq \pm 25$ \\
\hline
\end{tabular}

\subsection{Thiết lập mô hình MIKE SHE}

Địa hình khu vực tính toán được xử lý từ số liệu DEM khu vực Trà Khúc-Sông Vệ bởi công cụ hỗ trợ của ArcGIS. Mô hình MIKE SHE cho phép tiếp nhận dữ liệu dạng lưới .dfs2, dạng đường/điểm shp file (Hình $5 \mathrm{a}$ ). Địa hình miền tính của lưu vực nghiên cứu được xác định danh giới cho cả vùng (Hình $5 b$ ). Số liệu mưa, bốc hơi được lấy từ mô hình số trị IFS, cách xử lý và tích hợp số liệu mưa vào mô hình được tiến hành thông qua quá trình tiền xử lý (pre-processing) để tạo thành file .dfs2 làm đầu vào cho mô hình MIKE SHE (Hình 5c). Bản đồ thảm phủ thực vật được xử lý từ bản đồ thảm phủ thực vật toàn quốc (Hình 5d). Thông số nhám Manning (n) được thiết lập cho toàn bộ lưu vực (Hình $5 \mathrm{e}$ ). Bản đồ sử dụng đất được xử lý từ bản đồ sử dụng đất toàn quốc (Atlas Việt nam) trong đó tiến hành thiết lập phân loại đất phù hợp đối với lưu vực nghiên cứu (Hình 5f).
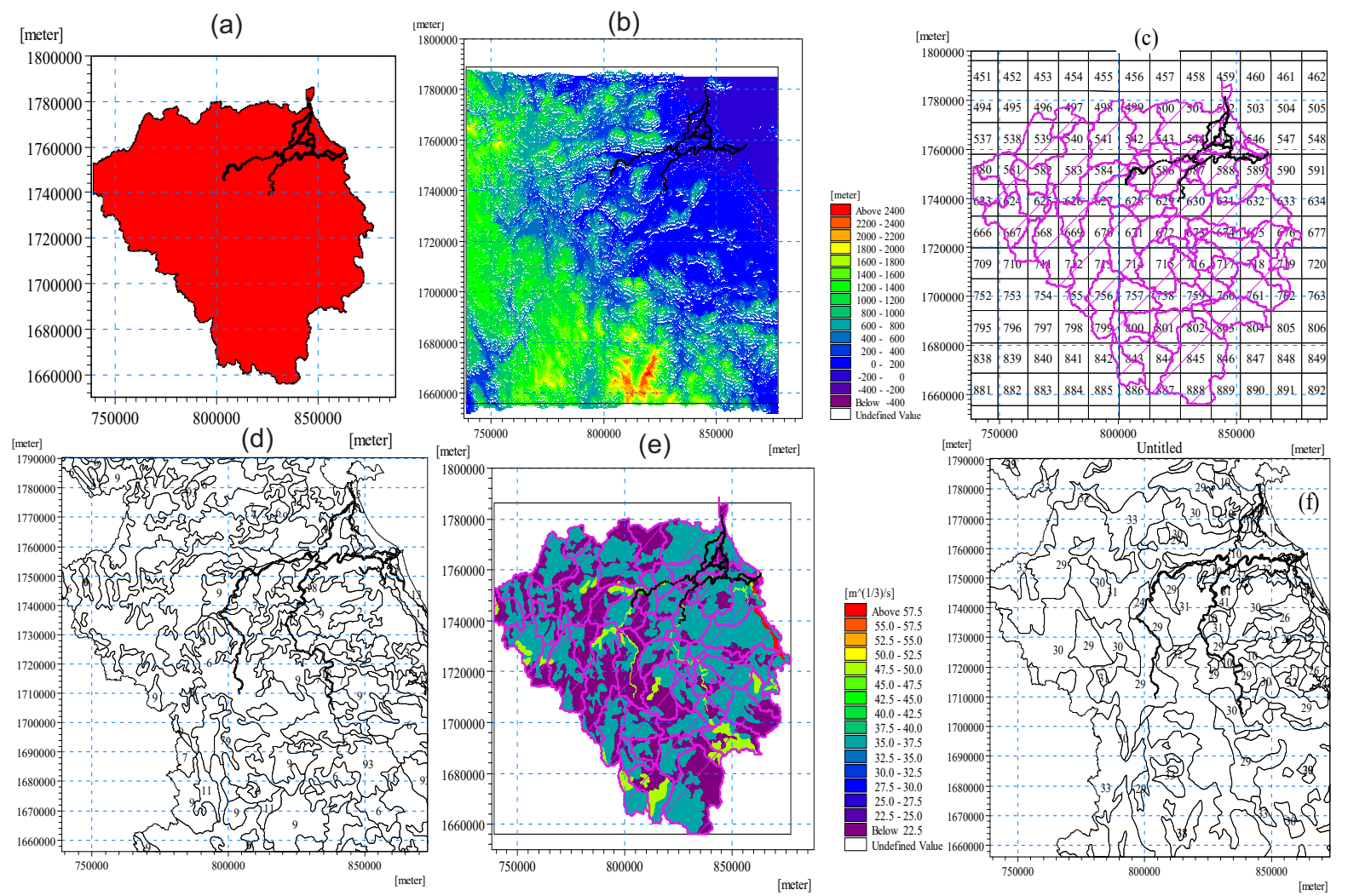

Hình 5. (a) Thiết lập vùng tính và lưới tính; (b) Thiết lập địa hình vùng tính; (c) Thiết lập biên khí tuợng; (d) Thiết lập các thông số thảm phủ thực vật; (e) Thiết lập thông số nhám; (f) Thiết lập phân loại đất. 


\subsection{Thiết lập mô hình MIKE 11}

Mô hình MIKE 11 được thiết lập gồm tổng số 210 mặt cắt được phân bố trên các sông chính và hệ thống sông nhánh của lưu vực Vu Gia-Thu Bồn. Hệ thống mạng thủy lực được thiết lập trong mô hình MIKE 11 được thể hiện trên hình
6. Để phục vụ cho quá trình hiệu chỉnh và kiểm định mô hình thủy văn MIKE SHE và mô hình thủy lực MIKE 11, nghiên cứu sử dụng số liệu lưu lượng thực đo tại các trạm Thành Mỹ, Nông Sơn; số liệu mực nước thực đo tại 04 trạm Hội Khách, Ái Nghĩa, Giao Thủy và Câu Lâu.

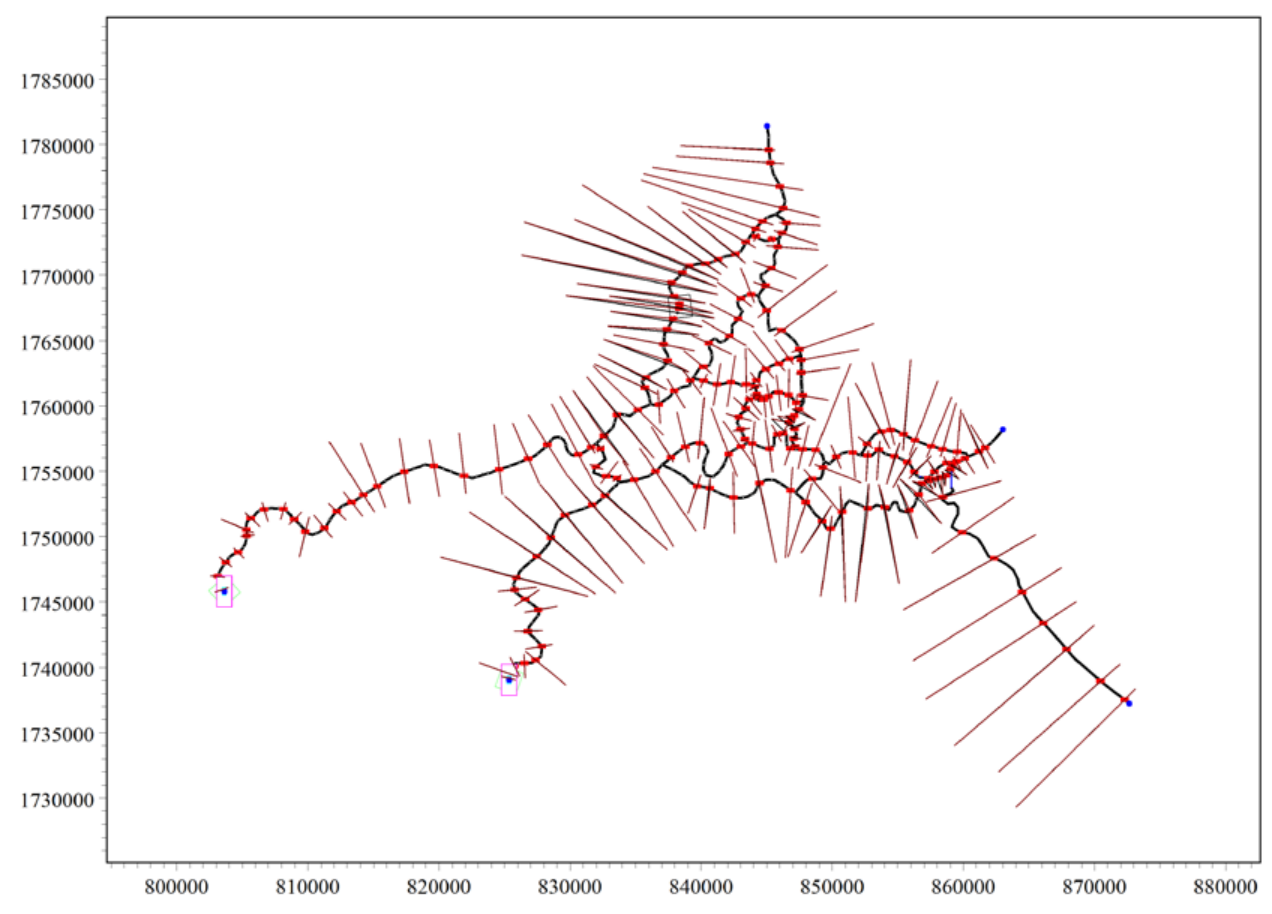

Hình 6. So đồ mạng lưới thủy lực lưu vực sông Vu Gia-Thu Bồn

\section{Kết quả và thảo luận \\ 3.1 Hiệu chỉnh và kiểm định mô hình MIKE} SHE

Quá trình hiệu chỉnh và kiểm định mô hình MIKE SHE sử dụng số liệu thực đo tại hai trạm Nông Sơn (sông Thu Bồn) và trạm Thành Mỹ (sông Vu Gia). Quá trình hiệu chỉnh mô hình sử dụng số liệu thực đo của 03 trận lũ: trận lũ 1 từ $23 / 9$ đến $14 / 10 / 2012$; trận lũ 2 từ $13 / 10$ đến 19/10/2013 và trận lũ 3 từ 14/11 đến 20/11/2014 (Hình 7a-7f). Quá trình kiểm định mô hình được lựa chọn với 03 trận lũ: trận lũ 1 từ $2 / 11$ đến 27/11/2014; trận lũ 2 từ 22/10 đến 21/11/2015 và trận lũ 03 từ 26/11 đến 11/12/2016 (Hình 7g71). Nghiên cứu áp dụng 03 chỉ số NSE, RSR và PBIAS để đánh giá kết quả trong quá trình hiệu chỉnh và kiểm định mô hình. Tổng hợp kết quả đánh giá mô hình đối với quá trình hiệu chỉnh và kiểm định được thể hiện trong bảng 2. Chỉ số NSE trong quá trình hiệu chỉnh tại hai trạm Nông
Sơn và Thành Mỹ dao động từ 0,78 - 0,90; giá trị RSR dao động từ 0,16 - 0,47; giá trị PBIAS (\%) dao động từ $-8,3$ đến 8,84 . Chỉ số NSE trong quá trình kiểm định mô hình tại hai trạm Nông Sơn và Thành $\mathrm{Mỹ} \mathrm{dao} \mathrm{động} \mathrm{từ} 0,82-0,93$; giá trị RSR dao động từ $0,22-0,37$; giá trị PBIAS (\%) dao động từ $-8,69$ đến 8,62 (PBIAS $< \pm 10$ ). Kết quả tính toán chỉ ra rằng mức độ trung bình của các giá trị mô phỏng dòng chảy được đánh giá là rất tốt $(\mathrm{PBIAS}< \pm 10)$ trong cả hai quá trình hiệu chỉnh và kiểm định mô hình. So sánh kết quả đánh giá với tiêu chí đánh giá tổng hợp trong bảng 1 cho thấy kết quả tính toán và thực đo trong cả hai quá trình hiệu chỉnh và kiểm định là rất tốt. Vì vậy, bộ thông số của mô hình MIKE SHE sẽ tiếp tục được sử dụng cho việc tính toán làm làm đầu vào cho mô hình thủy lực MIKE 11 và MIKE 11 GIS trong việc mô phỏng, cảnh báo ngập lụt cho khu vực hạ lưu. 


\section{BÀI BÁO KHOA HỌC}

Bảng 2. Tổng hợp kết quả đánh giá trong quá trình hiệu chỉnh và kiểm định mô hình MIKE-SHE

\begin{tabular}{|c|c|c|c|c|c|c|c|}
\hline \multicolumn{2}{|c|}{ Quá trình } & \multicolumn{3}{|c|}{ Hiệu chỉnh } & \multicolumn{3}{|c|}{ Kiểm định } \\
\hline \multicolumn{2}{|c|}{ Trận lũ } & \multicolumn{3}{|c|}{ Trận lũ 10/2012 } & \multicolumn{3}{|c|}{ Trận lũ 11/2014 } \\
\hline Trạm & Sông & NSE & PBIAS (\%) & RSR & NSE & PBIAS (\%) & RSR \\
\hline Thành Mỹ & Vu Gia & 0,78 & -8.3 & 0,47 & 0,82 & $-8,69$ & 0,28 \\
\hline Nông Sơn & Thu Bồn & 0,86 & 8,61 & 0,16 & 0,91 & 8,62 & 0,27 \\
\hline \multicolumn{2}{|c|}{ Trận lũ } & \multicolumn{3}{|c|}{ Trận lũ 10/2013 } & \multicolumn{3}{|c|}{ Trận lũ 09/2016 } \\
\hline Trạm & Sông & NSE & PBIAS (\%) & RSR & NSE & PBIAS (\%) & RSR \\
\hline Thành Mỹ & Vu Gia & 0,84 & $-6,36$ & 0,25 & 0,84 & $-2,56$ & 0,25 \\
\hline Nông Sơn & Thu Bồn & 0,86 & 8,84 & 0,21 & 0,86 & 6,94 & 0,37 \\
\hline \multicolumn{2}{|c|}{ Trận lũ } & \multicolumn{3}{|c|}{ Trận lũ 11/2013 } & \multicolumn{3}{|c|}{ Trận lũ 11/2016 } \\
\hline Trạm & Sông & NSE & PBIAS (\%) & RSR & NSE & PBIAS (\%) & RSR \\
\hline Thành Mỹ & Vu Gia & 0,88 & $-5,26$ & 0,19 & 0,85 & 3,2 & 0,22 \\
\hline Nông Sơn & Thu Bồn & 0,90 & 4,7 & 0,31 & 0,93 & 7,92 & 0,27 \\
\hline
\end{tabular}

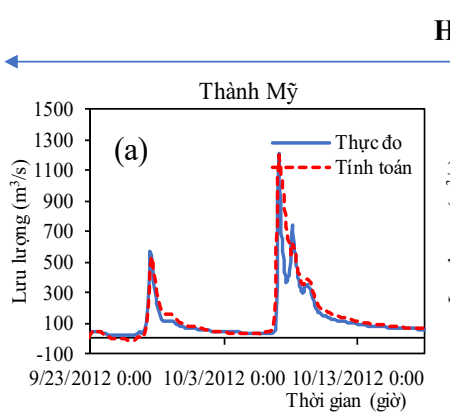

Hiệu chỉnh

Kiểm định
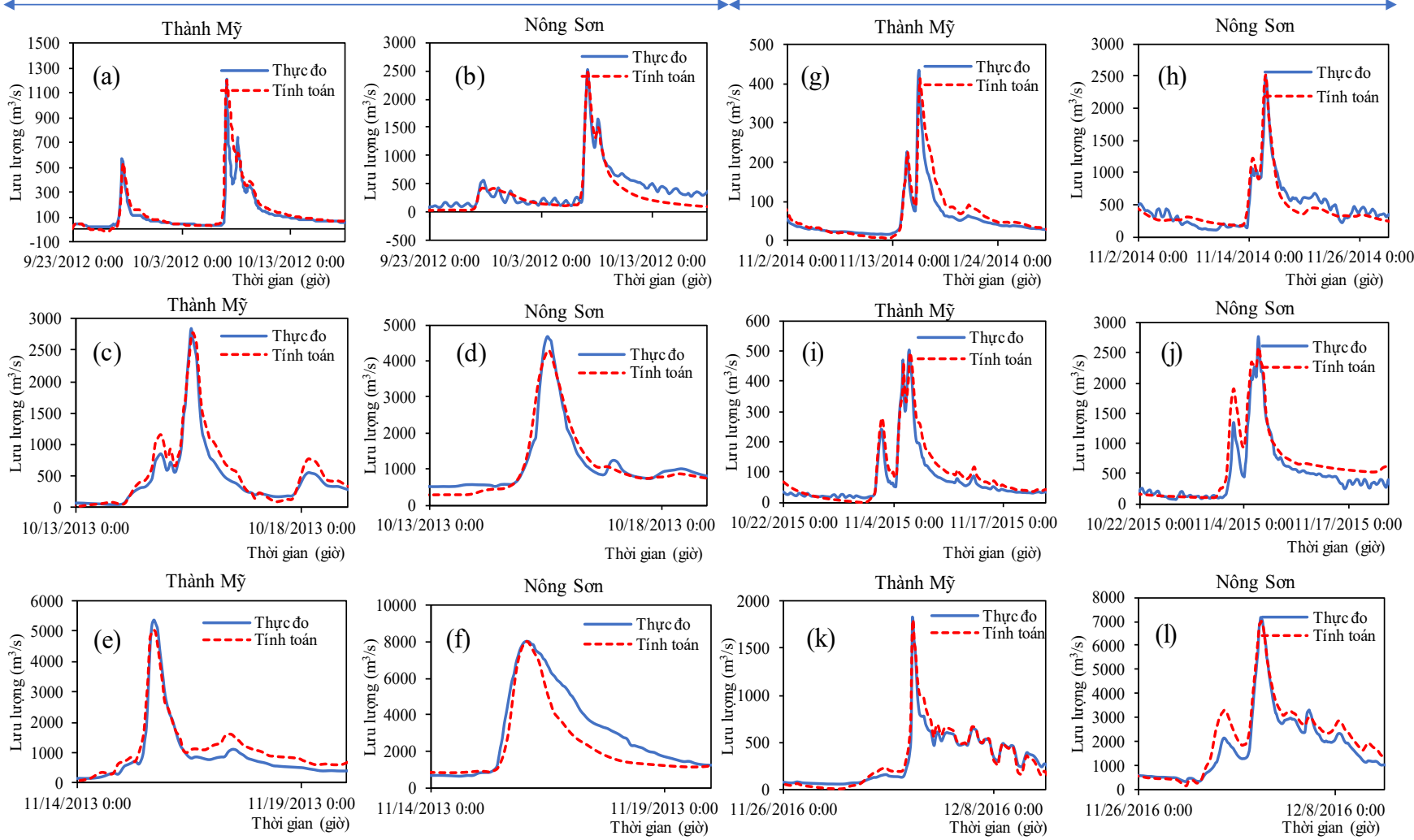

Hình 7. Kết quả hiệu chỉnh và kiểm định mô hình với 03 trận lũ năm 2012-2013 và 03 trận lũ năm 2014-2016 tai hai trạm: (a, c, e, g, i, k) Thành Mỹ; (b, d, f, h, j, l) Nông Sơn

3.2 Kết quả hiệu chỉnh và kiểm định mô hình MIKE 11

Quá trình hiệu chỉnh và kiểm định mô hình thủy lực MIKE 11 sử dụng số liệu thực đo tại 04 trạm: Hội Khách, Ái Nghĩa (sông Vu Gia) và
Giao Thủy, Câu Lâu (sông Thu Bồn). Quá trình hiệu chỉnh được lựa chọn với 03 trận lũ điển hình: trận lũ 1 từ $1 / 10$ đến $15 / 10 / 2012$; trận lũ 2 từ $7 / 10$ đến $22 / 10 / 2013$; trận lũ 3 từ $11 / 11$ đến 26/11/2013 (Hình 8). Quá trình kiểm định được 
lựa chọn với 03 trận lũ điển hình: trận lũ 1 từ $8 / 11$ đến $28 / 11 / 2014$; trận 1 ũ 2 từ $7 / 9$ đến 19/9/2016 và trận lũ 3 từ 26/11 đến 10/12/2016
(Hình 9). Bảng tổng hợp đánh giá kết quả hiệu chỉnh và kiểm định mô hình sử dụng 03 chỉ số NSE, RSR và PBIAS để đánh giá (Bảng 3 ).

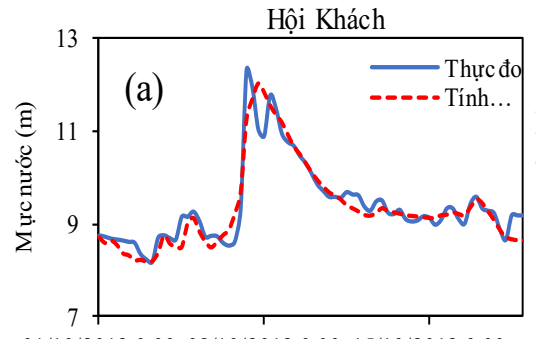

01/10/2012 0:00 08/10/2012 0:00 15/10/2012 0:00 Thời gian (giờ) Ái Nghĩa
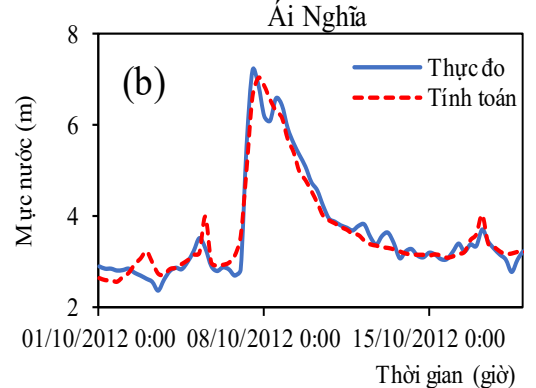
Giao Thủy

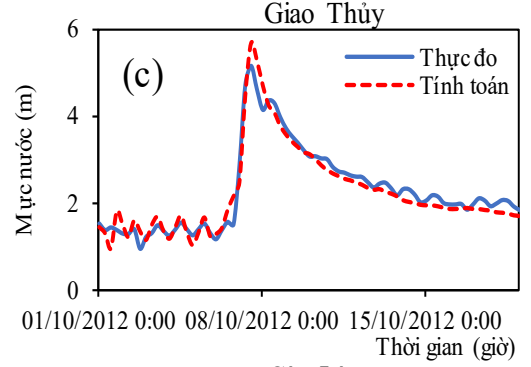
Câu Lâu

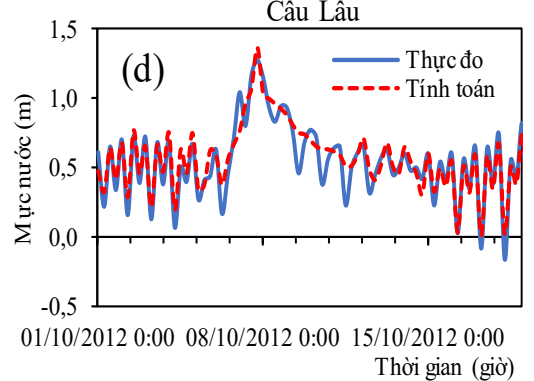

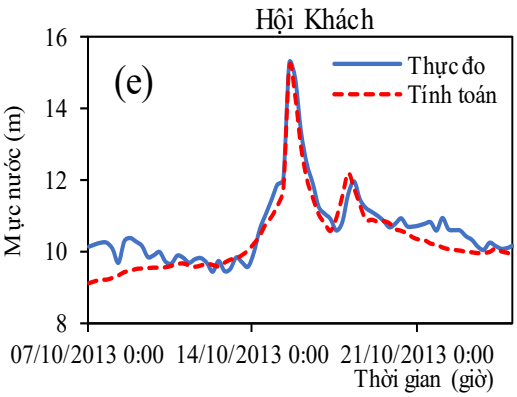

Ái Nghĩa
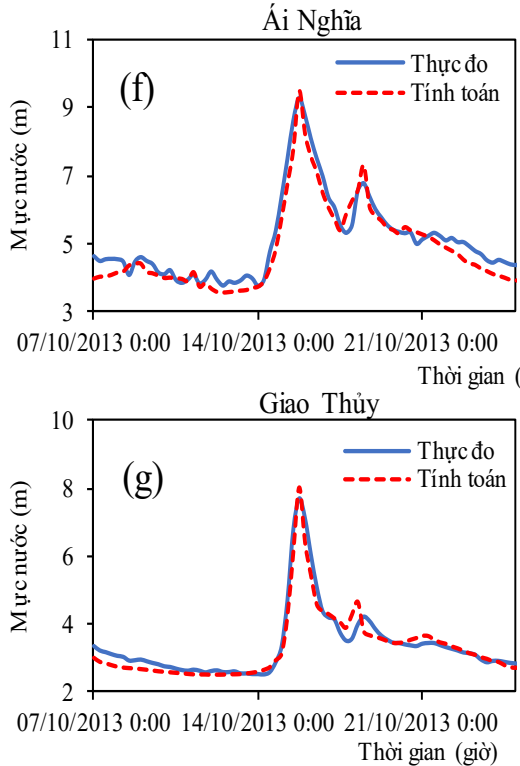

Câu Lâu

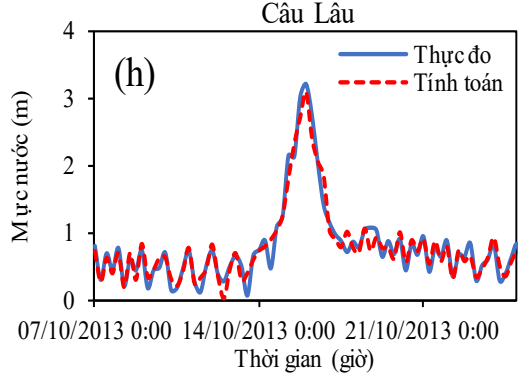

Hội Khách

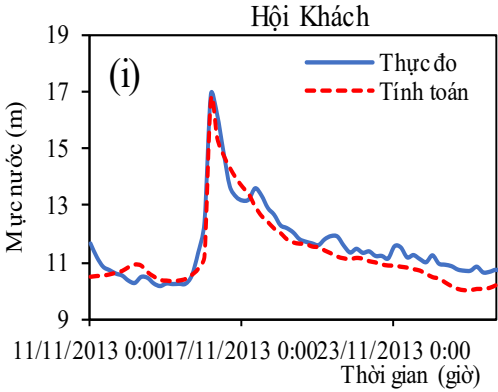

Ái Nghĩa

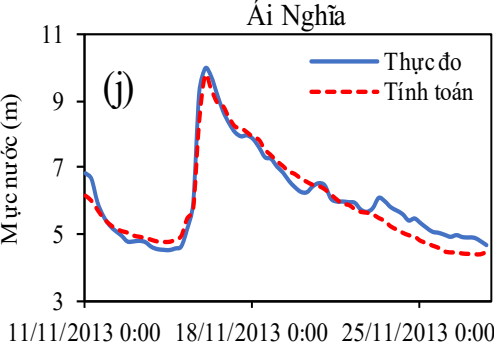

Giao Thừi gian (giờ)

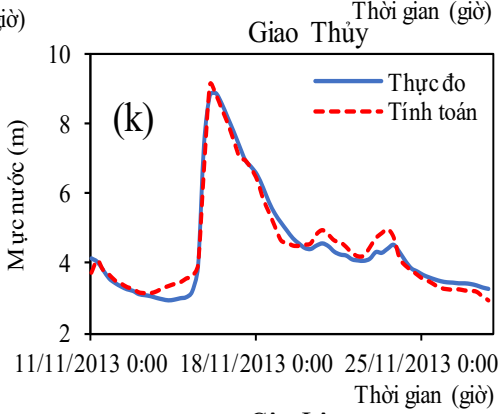

Câu Lâu

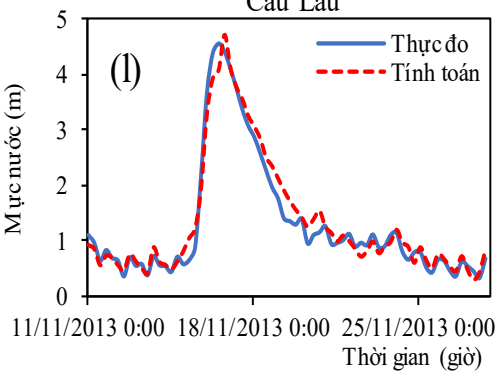

Hình 8. Kết quả hiệu chỉnh mô hình thủy lực MIKE 11 với 03 trận lũ năm 2012-2013 tại 04 trạm: (a, e, i) Hội Khách; (b, f, j) Ái Nghĩa; Giao Thủy (c, g, k) và Câu Lâu $(d, h, l)$

Kết quả đánh giá theo chỉ số NSE có giá trị dao động từ $0,85-0,94$ đối với quá trình hiệu chỉnh; 0,74 - 0,92 đối với quá trình kiểm định mô hình. Chỉ số RSR có giá trị dao động từ 0,02 - 0,37 đối với quá trình hiệu chỉnh với 03 trận lũ năm 2012 và 2013; RSR có giá trị dao động từ 0,12 - 0,6 đối với quá trình kiểm định mô hình. Giá trị PBIAS (\%) có giá trị dao động từ 1,4 14,6 đối với cả hai quá trình hiệu chỉnh và kiểm định mô hình. So sánh tổng hợp kết quả đánh giá mô hình trong cả hai quá trình hiệu chỉnh và kiểm định với tiêu chí đánh giá 03 chỉ số trong bảng 1 chỉ ra rằng mô hình mô phỏng tốt quá trình diễn toán thủy lực trong sông. Kết quả so sánh đường quá trình mực nước tính toán và thực đo có sự tương đồng cao về pha và biên độ dao động đối với cả hai quá trình hiệu chỉnh và kiểm định mô hình. Bộ thông số thủy lực của mô hình sẽ được sử dụng để mô phỏng, cảnh báo ngập lụt cho khu vực hạ lưu trong mô hình MIKE 11 GIS. 
Bảng 3. Tổng hợp kết quả đánh giá trong quá trình hiệu chỉnh và kiểm định mô hình

\begin{tabular}{|c|c|c|c|c|c|c|c|}
\hline \multicolumn{2}{|c|}{ Quá trình } & \multicolumn{3}{|c|}{ Hiệu chỉnh } & \multicolumn{3}{|c|}{ Kiểm định } \\
\hline \multicolumn{2}{|c|}{ Trận lũ } & \multicolumn{3}{|c|}{ Trận lũ 10/2012 } & \multicolumn{3}{|c|}{ Trận lũ 11/2014 } \\
\hline Trạm & Sông & NSE & PBIAS (\%) & RSR & NSE & PBIAS (\%) & RSR \\
\hline Hội Khách & Vu Gia & 0,85 & 2,3 & 0,3 & 0,82 & 2,5 & 0,6 \\
\hline Ái Nghĩa & Vu Gia & 0,92 & 5,6 & 0,2 & 0,85 & 4,6 & 0,58 \\
\hline Giao Thủy & Thu Bồn & 0,94 & 7,8 & 0,3 & 0,75 & 8,5 & 0,26 \\
\hline Câu Lâu & Thu Bồn & 0,90 & 12,4 & 0,02 & 0,89 & 10 & 0,12 \\
\hline \multicolumn{2}{|c|}{ Trận lũ } & \multicolumn{3}{|c|}{ Trận lũ 10/2013 } & \multicolumn{3}{|c|}{ Trận lũ 09/2016 } \\
\hline Trạm & Sông & NSE & PBIAS (\%) & RSR & NSE & PBIAS (\%) & RSR \\
\hline Hội Khách & Vu Gia & 0,92 & 3,1 & 0,01 & 0,79 & 4 & 0,6 \\
\hline Ái Nghĩa & Vu Gia & 0,87 & 6 & 0,3 & 0,84 & 8 & 0,36 \\
\hline Giao Thủy & Thu Bồn & 0,89 & 5,8 & 0,2 & 0,74 & 12 & 0,54 \\
\hline Câu Lâu & Thu Bồn & 0,90 & 14,6 & 0,2 & 0,76 & 12 & 0,14 \\
\hline \multicolumn{2}{|c|}{ Trận lũ } & \multicolumn{3}{|c|}{ Trận lũ 11/2013 } & \multicolumn{3}{|c|}{ Trận lũ 11/2016 } \\
\hline Trạm & Sông & NSE & PBIAS (\%) & RSR & NSE & PBIAS (\%) & RSR \\
\hline Hội Khách & Vu Gia & 0,82 & 3,6 & 0,37 & 0,84 & 0,5 & 0,42 \\
\hline Ái Nghĩa & Vu Gia & 0,88 & 4,7 & 0,25 & 0,86 & 1,4 & 0,30 \\
\hline Giao Thủy & Thu Bồn & 0,91 & 5,2 & 0,18 & 0,90 & 3,2 & 0,34 \\
\hline Câu Lâu & Thu Bồn & 0,93 & 13 & 0,19 & 0,92 & 2,2 & 0,23 \\
\hline
\end{tabular}

3.2 Cảnh báo ngập lụt hạ lưu sông Vu Gia-

\section{Thu Bồn}

Theo số liệu tổng hợp thống kê được từ Trung tâm Dự báo khí tượng thủy văn quốc gia, lũ trên lưu vực Vu Gia-Thu Bồn vượt mức báo động III và đạt mức lũ lịch sử được ghi nhận là năm 1964 tại vị trí trạm Giao Thủy (sông Thu Bồn), năm 2007 tại vị trí trạm Câu Lâu (sông Thu Bồn), và năm 2009 tại trạm Ái Nghĩa (sông Vụ Gia) (Bảng 4). Trong chuỗi số liệu thu thập đánh giá từ năm 2012-2017, trận lũ tháng 11/2016 được sử dụng để kiểm định chất lượng của mô hình với mực nước đỉnh lũ tính toán và thực đo đều vượt mức báo động II (BĐII) (Hình 10). Trong bối cảnh biến đồi khí hậu ở nước ta hiện nay với việc ngày càng xuất hiện nhiều các loại hình thiên tai nguy hiểm trong đó có thiên tai do lũ, ngập lụt gây ra. Vì vậy, nghiên cứu xây dựng trước những bản đồ cảnh báo nguy cơ ngập theo mức báo động và đặc biệt mực nước lũ lịch sử đóng vai trò hết sức quan trọng và cấp thiết. Trong nghiên cứu này, bộ thông số mô hình thủy văn (MIKE SHE) và bộ thông số thủy lực của mô hình (MIKE 11) được đánh giá là tốt đối với cả hai quá trình hiệu chỉnh và kiểm định mô hình. Nghiên cứu đã sử dụng số liệu trận lũ xảy ra vào tháng 10/2009 để mô phỏng, tính toán khả năng và mức độ ngập trên mức báo động $\mathrm{BĐII,}$ BĐIII và mức lũ lịch sử xét tại vị trí Câu Lâu (Hình 11). Kết quả thống kê đánh giá mức độ ngập theo mức báo động và mức lũ lịch sử được chỉ ra trên hình 11 . 
Hội Khách

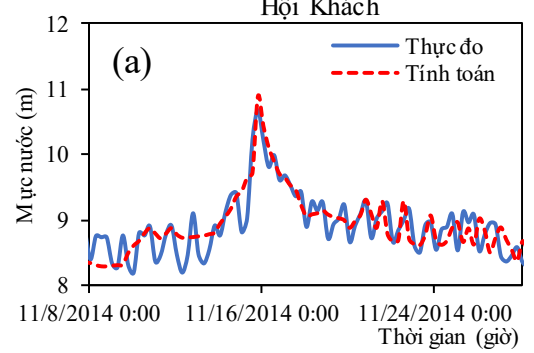

Ái Nghĩa
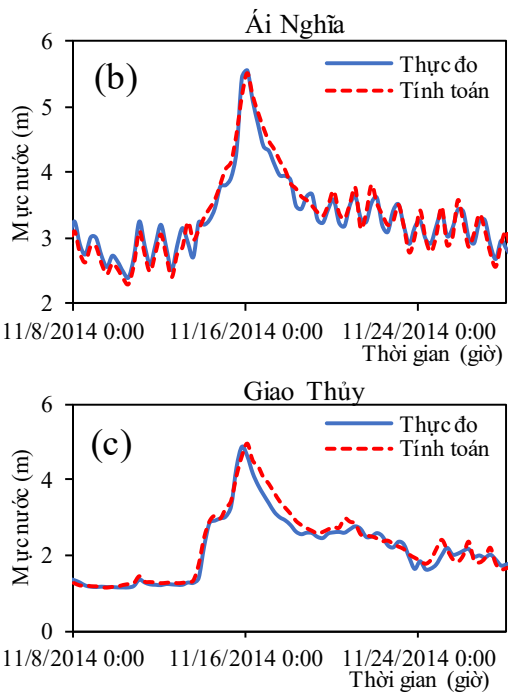

Câu Lâu

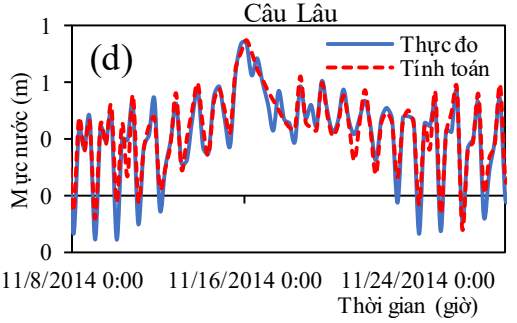

Hội Khách
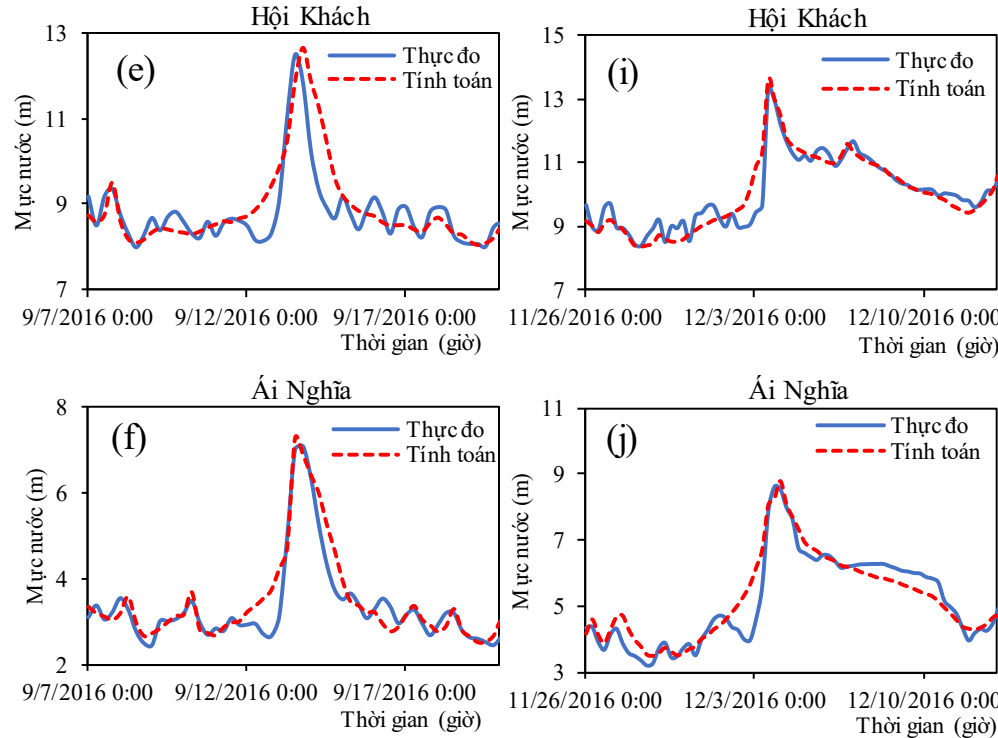

Giao Thủy

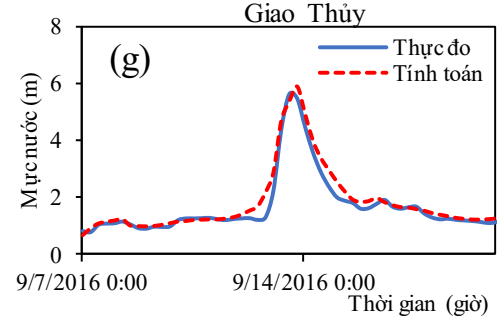

Câu Lâu

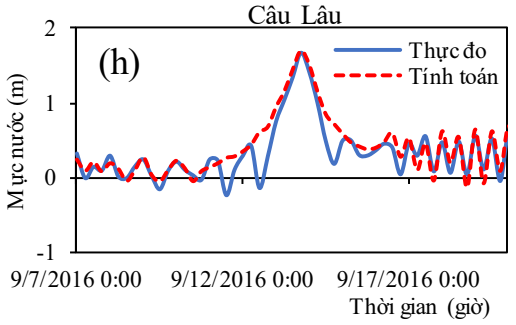

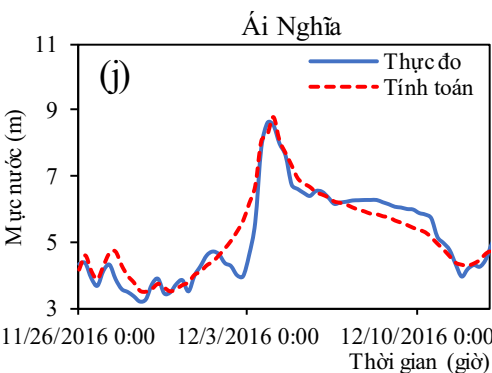

Giao Thủy
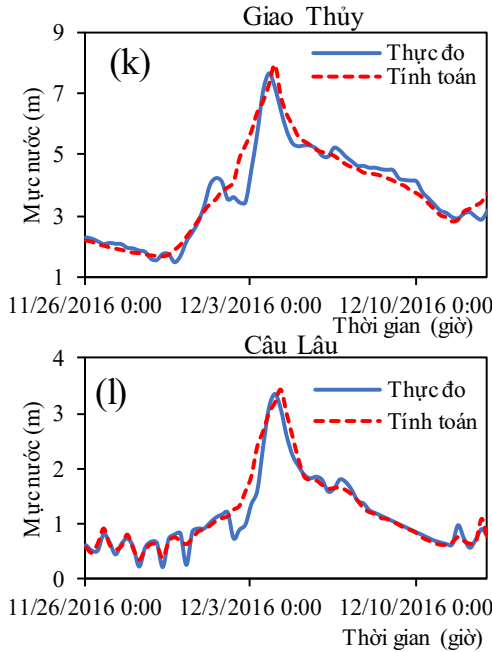
$\begin{array}{ccc}11 / 26 / 2016 \text { 0:00 12/3/2016 0:00 12/10/2016 0:00 } & \text { Thời gian (giờ) }\end{array}$

Hình 9. Kết quả kiểm định mô hình thủy lực MIKE 11 với 01 trận lũ năm 2014 và 02 trận lũ năm 2016 tại 04 trạm: (a, e, i) Hội Khách; (b, f, j) Ái Nghĩa; Giao Thủy (c, g, k) và Câu Lâu (d, h, l)

Bảng 4. Mức báo động và mức lũ lịch sủ trên các sông Vu Gia-Thu Bồn

\begin{tabular}{ccccccc}
\hline STT & Sông & Trạm & BĐI & BĐII & BĐIII & Hmax/năm \\
\hline 1 & Vu Gia & Ái Nghĩa & 650 & 800 & 900 & $1077 / 2009$ \\
2 & Thu Bồn & Giao Thủy & 620 & 750 & 860 & $1006 / 1964$ \\
3 & Thu Bồn & Câu Lâu & 200 & 300 & 400 & $539 / 2007$ \\
\hline
\end{tabular}




\section{BÀI BÁO KHOA HỌC}

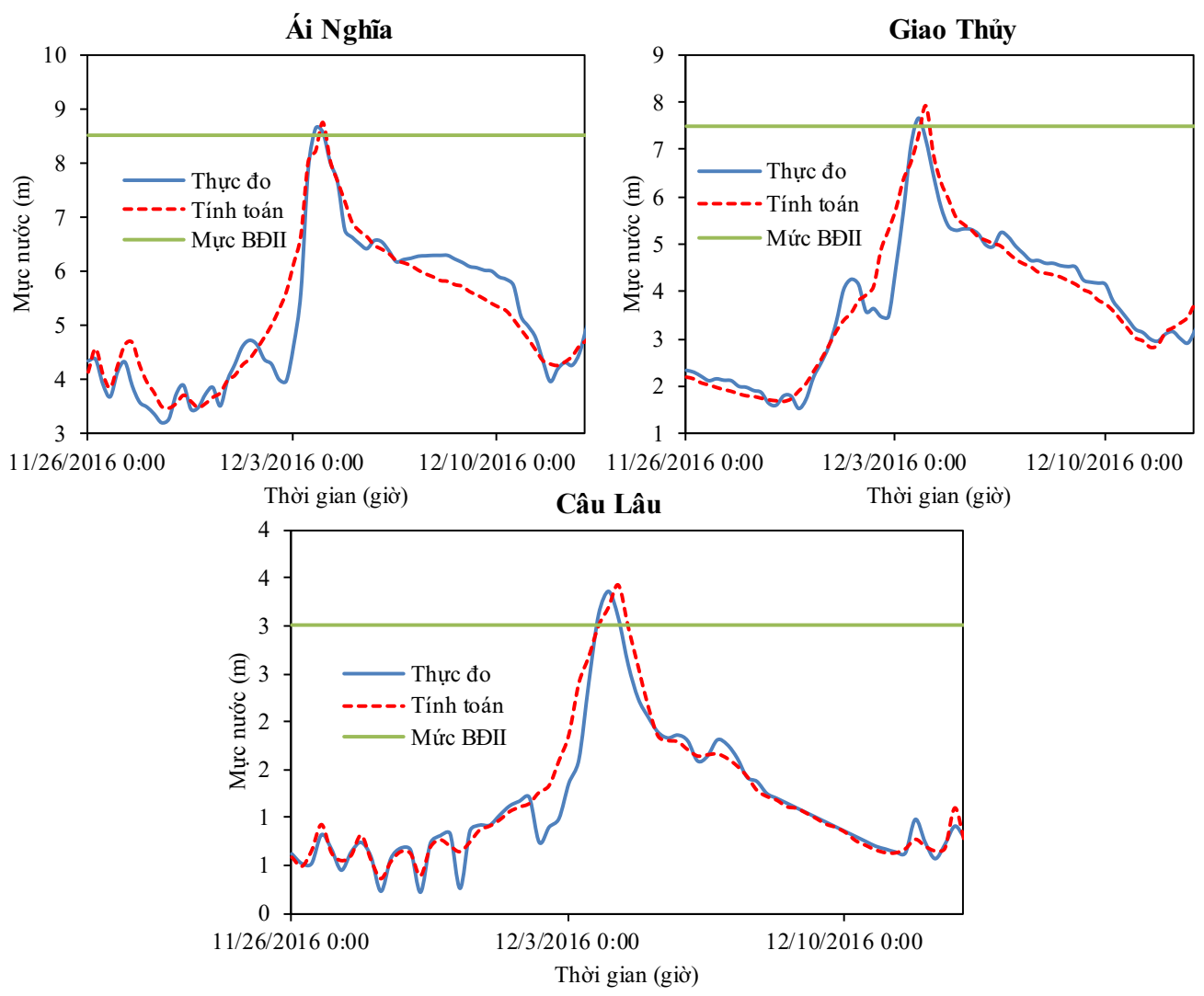

Hình 10. Kết quả so sánh mục nước tính toán và thực đo với mức báo động lũ tại một số vị trí trên lư vục sông Vu Gia-Thu Bồn

\section{Kết luận}

Nghiên cứu đã áp dụng kết hợp sử dụng mưa từ mô hình số trị IFS làm đầu vào cho các mô hình thủy văn MIKE SHE, mô hình thủy lực MIKE 11 và mô hình mô phỏng ngập lụt MIKE 11 GIS. Nghiên cứu đã đạt được một số kết quả chính như sau:

+ Khai thác và sử dụng được sản phẩm của mô hình số trị IFS trong bài toán mô phỏng, tính toán lũ, cảnh báo ngập lụt cho một lưu vực cụ thể (Vu Gia-Thu Bồn).
+ Đánh giá quá trình hiệu chỉnh và kiểm định mô hình thủy văn MIKE SHE để tìm ra được bộ thông số phù hợp cho việc mô phỏng tính toán dòng chảy làm đầu vào cho mô hình thủy lực MIKE 11.

+ Đánh giá được quá trình hiệu chỉnh và kiểm định mô hình thủy lực MIKE 11 để tìm ra bộ thông số thủy lực phù hợp cho việc mô phỏng tính toán bản đồ cảnh báo ngập lụt theo cấp báo động và mức lũ lịch sử cho khu vực hạ lưu. 


\section{BÀI BÁO KHOA HỌC}
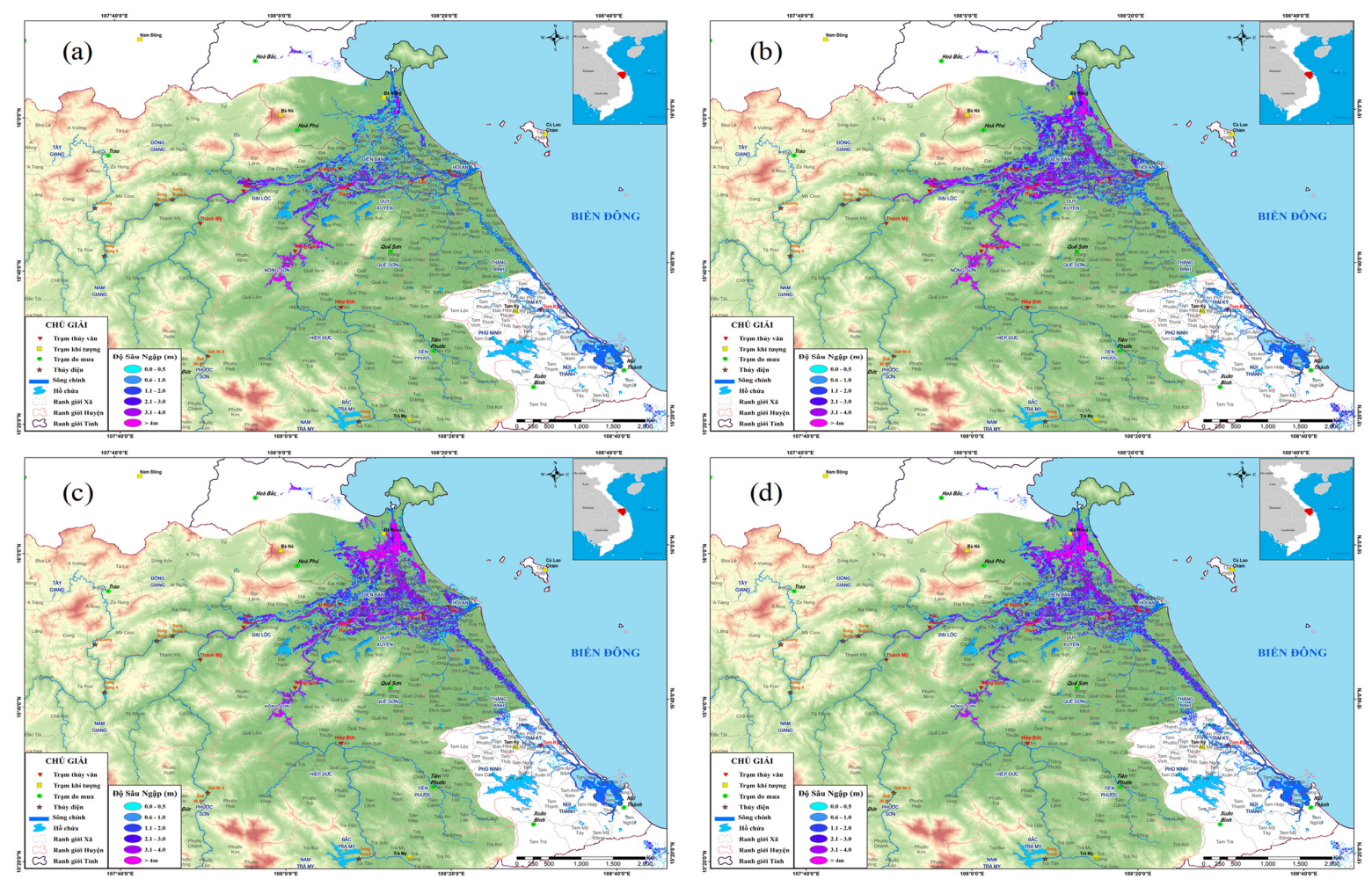

Hình 11. Kết quả xây dụng bản đồ ngập lụt theo múc báo động lũ và múc lũ lịch sư năm 2009 tại khu vục hạ lưu sông Vu Gia-Thu Bồn: (a) 3,20m (>BĐII= 3,0m); (b) 4,20m (>BDIII=4,0m); (c) 5,0m (BĐIII); (d) 5,40m (> HLịch sử = 5,39m) tại trạm Câu Lâu

Lò̀i cảm ơn: Nghiên cứu này là một phần kết quả của đề tài nghiên cưu khoa học và phát triển công nghệ cấp Bộ: "Nghiên cứu ứng dụng số liệu dụ báo của Trung tâm Dự báo thời tiết hạn vìa Châu Âu để xây dưng các phương án dụ báo lũ 5 ngày cho các sông chính ở Trung Trung Bộ”, mã số: TNMT.2018.05.35.

\section{Tài liệu tham khảo}

1. Bùi Minh Tăng (2014), Báo cáo tổng kết đề tài "Nghiên cứu xây dụng công nghệ dụ báo mưa lớn thời hạn 2-3 ngày phục vu công tác cảnh báo sóm lũ lụt khu vục miền Trung Việt Nam”.

2. Đặng Ngọc Tĩnh (2012), Báo cáo tổng kết đề tài "Nghiên cưu ứng dụng số liệu vệ tinh, mua dụ báo số trị kết hợp số liệu bề mặt trong dụ báo lu hệ thống sông Hồng- Thái Bình".

3. Bùi Đình Lập (2017), Báo cáo tổng kêt đề tài "Nghiên cứu xây dụng công nghê dụ báo dòng chảy lũ đến các hồ chứa lớn trên hẹ thống sông Hồng”.

4. Trần Hồng Thái, Đoàn Quang Trí, Đinh Việt Hoàng (2018), Nghiên cúu mô phỏng tác động của sóng và nước dâng bão khu vục ven biển miền Trung. Tạp chí Khí tượng Thủy văn, 687, 1-14.

5. Tran Tho Dat, Dinh Duc Truong, Doan Quang Tri, Tran Quang Tien (2018). Applications of numerical modelling for the study on storm surge in typhoon Xangsane in the central coast of Vietnam. Tropical Cyclone Research and Review, 7 (3), 179-192.

6. Tran Tho Dat, Doan Quang Tri, Dinh Duc Truong, Nguyen Ngoc Hoa (2019). Application of Mike Flood Model in Inundation Simulation with the Dam-break Scenarios: a Case Study of DakDrinh Reservoir in Vietnam. International Journal of Earth Sciences and Engineering, 12 (01), 6070. 


\section{BÀI BÁO KHOA HỌC}

7. Dự án nhiệm vụ chuyên môn (2013-2015), Xây dưng công nghệ dụ báo lũ hạn ngắn phục vụ điều tiết hồ chứa cho lưu vực sông Vu Gia - Thu Bồn và luu vực sông Ba.

8. Vũ Đức Long (2014), Nghiên cúu xây dưng công nghệ cảnh báo, dụ báo lũ và cảnh báo ngập lut cho các sông chính ở Quảng Bình, Quảng Trị.

9. Vũ Đức Long (2015), Báo cáo tổng kết đề tài "Nghiên cứu ứng dụng thử nghiệm mô hình TELEMAC 2D tính toán lũ và cảnh báo ngập lụt cho vùng hạ luu sông Trà Khúc - Sông Vệ".

10. Nguyen Thi Mai Linh, Doan Quang Tri, Tran Hong Thai, Nguyen Cao Don (2018), Application of a two-dimensional model for flooding and floodplain simulation: Case study in Tra KhucSong Ve river in Viet Nam. Lowland Technology International, 20 (3), 367-378.

11. Hoàng Anh Huy (2016), Nghiên cưu khả năng ứng dụng mô hình MIKE-SHE để mô phỏng độ ẩm trong đất, áp dụng thi điểm cho dòng chính khu vực sông La.

12. Trần Hồng Thái, Đoàn Quang Trí, Trần Đỗ Thủy Tuyên, Ngô Thanh Tâm, Bùi Thị Dịu (2019), Áp dụng mô hình MIKE SHE kết hợp sủ dụng sản phẩm mura dụ báo IFS dụ báo lưu lương đến hồ lưu vực sông Trà Khúc-Sông Vệ. Tạp chí Khí tượng Thủy văn, 697, 1-12.

13. Danish Hydraulic Institute (DHI), (2014a), MIKE SHE User Manual, Volume 1: User Guide, $370 \mathrm{p}$.

14. Danish Hydraulic Institute (DHI), (2014b), MIKE SHE User Manual, Volume 2: Reference Guide, $444 \mathrm{p}$.

15. Abbott, M.B., Bathurst, J.C., Cunge, J.A., O’Connell, P.E., Rasmussen, J. (1986a), An introduction to the European Hydrological System-Systeme Hydrologique Europeen, "SHE”, 1: history and philosophy of a physically-based, distributed modelling system. J. Hydrol. 87, 45-59.

16. Abbott, M.B., Bathurst, J.C., Cunge, J.A., O'connell, P.E., Rasmussen, J. (1986b), An introduction to the European Hydrological System Systeme Hydrologique Europeen, "SHE”, 2: Structure of a physically-based, distributed modelling system. J. Hydrol. 87, 61-77.

17. DHI (2017), MIKE 11, A modelling system for rivers and channel, user guide. http://manuals.mikepoweredbydhi.help/2017/Water_Resources/MIKE11_UserManual.pdf

18. Moriasi, D.N., Arnold, J.G., Liew, M.W. et al. (2007), Model evaluation guidelines for systematic quantifcation of accuracy in watershed simulations. Trans. ASABE 50, 885-900.

19. Moriasi, D., Wilson, B. (2012), Hydrologic and water quality models: use, calibration, and validation. Trans. ASABE 55, 1241-1247.

20. Mustafa, Y.M., Amin, M.S.M., Lee, T.S., Shariff, A.R.M. (2012), Evaluation of land development impact on a tropical watershed hydrology using remote sensing and GIS. J. Spat. Hydrol. 5, 16-30.

21. Bathurst, J.C., Ewen, J., Parkin, G., O’Connell, P.E., Cooper, J.D. (2004), Validation of catchment models for predicting land-use and climate change impacts. 3. Blind validation for internal and outlet responses. J. Hydrol. 287, 74-94.

22. Engel, B.A., Flanagan, D.C. (2006), Modeling and risk analysis of nonpoint-source pollution caused by atrazine using SWAT. Trans. ASABE 49, 667-678.

23. McCuen, R.H., Knight, Z., Cutter, A.G. (2006), Evaluation of the Nash-Sutcliffe efciency Index. J. Hydrol. Eng. 11, 597-602.

24. Nash, J.E., Sutcliffe, J.V. (1970), River flow forecasting through conceptual models part I-a discussion of principles. J. Hydrol. 10, 282-290.

25. Andersen, J., Refsgaard, J.C., Jensen, K.H. (2001), Distributed hydrological modelling of the Senegal River basin Model construction and validation. J. Hydrol. 247, 200-214.

26. Gupta, H.V., Sorooshian, S., Yapo, P.O. (1999), Status of automatic calibration for hydrologic models: comparison with multilevel expert calibration. J. Hydrol. Eng. 4, 135-143. 


\title{
APPLICATION HYDROLOGY-HYDRAULIC MODELS COMBINED WITH RAINFALL FORECASTING (IFS) IN FLOOD AND INNUNDATION WARNNING ON VU GIA-THU BON BASIN
}

\section{Doan Quang Tri ${ }^{1}$}

${ }^{1}$ Vietnam Journal of Hydrometeorology, Viet Nam Meteorological and Hydrological Administration

\begin{abstract}
The application of modeling in flood warning and forecasting has drawn much attention. In this study, the hydrological model MIKE SHE, the hydraulic model MIKE 11 and the MIKE 11 GIS model are combined to simulate flood warning at the downstream of the Vu Gia-Thu Bon River, Vietnam. The rainfall data from IFS numerical model are used as an input to hydraulic, hydrological models. The results of calibration and verification indicate that the application has a good ability to simulation. The calculation and simulation results of the calculated and measured water level and flow have high similarity in phase and amplitude of oscillation which are based on 03 indicators of NSE, RSR, and PBIAS. The simulation results of flood warning at the downstream which is in accordance with alarm levels and historical flood levels will produce statistical results to support responses to natural disasters.
\end{abstract}

Keywords: IFS, MIKE SHE, MIKE 11-MIKE 11 GIS, Inundation, Vu Gia-Thu Bon River basin. 